\title{
Tandem Mass Spectrometry
}

National Cancer Institute

\section{Source}

National Cancer Institute. Tandem Mass Spectrometry. NCI Thesaurus. Code C18142.

Mass spectrometers coupled in series. The targeted compound is selectively ionized, and its characteristic ions are separated from others in the mixture in the first mass spectrometer. The selected primary ions are then decomposed by collision, and from the resulting products the final mass analyzer selects secondary ions characteristic of the targeted compound. Tandem mass spectrometry can achieve specificities and sensitivities equivalent of those of methods such as radioimmunoassay and gas chromatography/mass spectrometry, while performing analyses in much shorter times. 